\title{
DIÁLOGO E ALTERIDADE: A EXTENSÃO NA TRANSVERSALIDADE DO ENSINO SUPERIOR
}

\author{
DIALOGUE AND ALTERITY: THE EXTENSION AS A PEDAGOGICAL DIMENSION IN HIGHER \\ EDUCATION \\ DIÁLOGO Y ALTERIDAD: LA EXTENSIÓN EN LA TRANSVERSALIDAD DE LA ENSEÑANZA \\ SUPERIOR
}

\author{
Thiago Henrique Barnabé Corrêa \\ E-mail: correa.uftm@gmail.com \\ Universidade Federal do Triângulo Mineiro - UFTM
}

\begin{abstract}
RESUMO
O presente texto busca promover uma leitura da extensão como componente formativo no ensino superior, considerando as cinco diretrizes que a norteiam, as quais são descritas na Política Nacional de Extensão Universitária (2012) e reiteradas nas Diretrizes para as Políticas de Extensão da Educação Superior Brasileira (2018): interação dialógica; interdisciplinaridade e interprofissionalidade; indissociabilidade ensino-pesquisa-extensão; impacto na formação do estudante; e, impacto e transformação social. A pertinência deste trabalho está na necessidade de se entender o papel central da universidade no século XXI, bem como sua função social e potencializadora na formação dos estudantes, adotando esta como uma possível lente de análise capaz de intervir em benefício coletivo.
\end{abstract}

PALAVRAS-CHAVE: Extensão. Educação universitária. Transformação social.

\section{ABSTRACT}

The present text seeks to promote a reading of the extension as a formative component in higher education, considering the five directives that guide it, which are described in the National Policy of University Extension (2012) and reiterated in the Guidelines for the Policies of Extension of Brazilian Higher Education (2018): dialogical interaction; interdisciplinarity and interprofessionality; teaching-research-extension indissociability; impact on student training; and, social impact and transformation. The pertinence of this work is the need to understand the central role of the university in the 21st century, as well as its social and potential role in the training of students, adopting this as a possible lens of analysis capable of intervening for collective benefit.

KEYWORDS: Extension. University education. Social transformation.

\section{RESUMEN}

El presente texto busca promover una lectura de la extensión como componente formativo en la enseñanza superior, considerando las cinco directrices que la orientan, las cuales se describen en la Política Nacional de Extensión Universitaria (2012) y reiteradas en las Directrices para las Politicas de Extensión de la Educación Superior Brasileña (2018): interacción dialógica; interdisciplinariedad e interprofesional; indudable enseñanza-investigación-extensión; impacto en la formación del estudiante; y el impacto y la transformación social. La pertinencia de este trabajo está en la necesidad de entender el papel central de la universidad en el siglo XXI, así como su función social y potencializadora en la formación de los estudiantes, adoptando esta como una posible lente de análisis capaz de intervenir en beneficio colectivo.

PALABRAS-CLAVE: Extensión. Formación universitária. Transformación social.

\section{APORTES INICIAIS}

Ao longo das últimas décadas, a extensão universitária tem passado por um intenso processo de clarificação conceitual à nível prático que caminha para a sua institucionalização. Das três dimensões constituintes da universidade, conhecidas como os pilares de sustentação acadêmica 


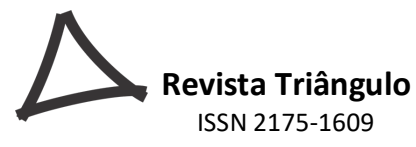

ISSN 2175-1609

[ensino, pesquisa e extensão], a extensão foi a última a surgir. Embora sua existência seja relevante, ao passo que garante uma espécie de retorno à sociedade, "na prática", de parcela do conhecimento produzido, não podemos negar a hierarquização e a desqualificação que essa sofre. Conforme Monteiro e Sacramento (2010) apontam, a supremacia do ensino e da pesquisa com relação à extensão se evidencia tanto no aporte de recursos (bolsas e órgãos de fomento vinculados), como nos processos avaliativos de desempenho docente que, comumente, inferioriza o prestígio e o mérito acadêmico daqueles que a praticam.

No contexto do processo de formação, o que poucos percebem é que a desqualificação da extensão universitária também compromete a qualidade do ensino e da pesquisa. Isso porque a indissociabilidade tão pregada entre ensino-pesquisa-extensão ainda é superficial, estando mais próxima de ser chamada de tentativa de interação.

Embora a extensão universitária tenha sido encarada por muito tempo como um adorno discursivo, sendo considerado extensão tudo aquilo que não se enquadra no ensino ou na pesquisa, felizmente já caminhamos para outros níveis de compreensão, os quais deixam de vê-la puramente sob a ótica assistencialista da academia, e porque não dizer benevolente e superior, para resgatar o elemento humano no diálogo entre o conhecimento dos "poderosos" e o conhecimento poderoso (erudito e popular), para então, nos fazer recordar que:

A extensão universitária é o que permanente e sistematicamente convoca a universidade para o aprofundamento de seu papel como instituição comprometida com a transformação social, que aproxima a produção e a transmissão de conhecimento de seus efetivos destinatários, cuidando de corrigir, nesse processo, as interdições e bloqueios, que fazem com que seja assimétrica e desigual a apropriação social do conhecimento, das ciências, das tecnológicas (De PAULA, 2013, p. 6, grifo nosso).

Nesse processo de ressignificação, a extensão se caracteriza como o principal elo de ligação entre a sociedade e a universidade, onde traz para o seio desta implicações político-sociais ao exigir de seus personagens uma nova postura, sobretudo aberta à inter e à transdisciplinaridade, que valorize, inclusive, o diálogo e a alteridade, ou seja, a capacidade de se enxergar no/pelo Outro; reconhecendo, assim, que a existência do eu-individual só é permitida mediante o contato real e efetivo com o Outro. Na interface dessas duas palavras (diálogo e alteridade) é impossível pensar a Extensão sem considerar a palavra interação, considerando-a como princípio deste pilar acadêmico ao resgatar que tal capacidade perpassa os níveis de consciência intra e interpessoal. 


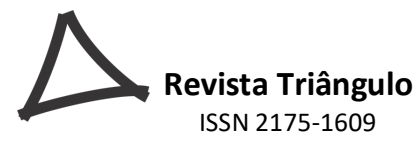

Longe de assumir a extensão sob o rótulo do verbo estender, como a universidade alongasse "suas mãos" para a comunidade externa, este texto se pauta na ideia já problematizada por Freire (2015) acerca do termo "extensão". Com isso, este ganha sentido como comunicação, interlocução e ação da academia junto à comunidade de modo a possibilitar o compartilhamento de saberes. Assim, o intuito deste texto é discutir a dimensão pedagógica (formativa) da extensão universitária ao considerar os seus cinco pilares/diretrizes: interação dialógica; interdisciplinaridade e interprofissionalidade; indissociabilidade ensino-pesquisa-extensão; impacto na formação do estudante; e, impacto e transformação do social.

\section{A EXTENSÃO COMO INSTRUMENTO DE TRANS-FORMAÇÃO HUMANA}

Ainda que o discurso de extensão não seja recente no mundo, tendo as primeiras manifestações na Inglaterra do século XIX (1871: Universidade de Cambridge), como "educação continuada" (Lifelong Education); no Brasil, foi só no início da década de 1960 que a extensão, como a conhecemos, passa a figurar nos documentos sob o discurso de compromisso social (NOGUEIRA, 2005; MIRRA, 2009).

Embora a Constituição de 1988 (Artigo 207) tenha consagrado o princípio da "indissociabilidade entre ensino, pesquisa e extensão", e a Lei de Diretrizes e Bases (LDB) de 1996 (Lei $n^{\circ}$ 9.394/96) a tenha estabelecido como uma das finalidades da universidade (Artigo 43), notase que professores, técnicos e estudantes ainda carecem de um entendimento pleno do significado da "extensão" na academia.

De modo geral, a cegueira, o desconhecimento e/ou a ingenuidade dos sujeitos da academia, fazem com que a própria prática extensionista (projetos e programas) a negue em sua essência, concebendo a ação da universidade muitas das vezes como um ato de caridade, e a comunidade externa como objetos que recebem, dócil e passivamente, os conteúdos que outros julgam ser pertinentes. Com isso, vale dizer que, este tipo de prática se contrapõe à ideia de dialogicidade. Isso porque a extensão serve, também, para dar voz ativa e visibilidade aos sujeitos "ocultos" da sociedade. Da mesma forma, legitimar o que fazemos na universidade, ou seja, dar utilidade ao nosso fazer.

Ao contrário do que muitos pensam, a primazia da extensão não está no levar conhecimento na proposição cínica do "faça o que eu digo" (GARCIA, 1995). Ser extensionista não se trata de 
impor, prescrever, ditar, senão de compartilhar, dialogar e interagir (interação dialógica) de modo a permitir a decisiva interligação entre a cultura científica e a cultura das humanidades (De PAULA, 2013).

$\mathrm{Na}$ extensão, o olhar verticalizado da academia é estéril e inerte para o fim da comunicação, do diálogo (troca de saberes). Contrária a essa concepção, as ações extensionistas são, ou deveriam ser: 1) situações educativas onde os envolvidos adquirem, mutuamente, o papel de sujeitos cognoscentes e mediatizados: co-participantes; e, 2) situações que requerem uma ação transformadora sobre a realidade. Isso implica abandonar a concepção de transmissão vertical e unilateral do conhecimento, no habitual serviço assistencial da universidade, levando em conta agora que extensão é, também, a mão inversa (CALDERÓN, 2003). Essa valorização do que vem da sociedade para a universidade num movimento de amorosidade e humildade é essencial para a prática da extensão.

Apoiado no conceito de ecologia de saberes de Boaventura de Souza Santos, a extensão ganha outro viés ao se tornar um:

(...) conjunto de práticas que promovem uma nova convivência ativa de saberes no pressuposto que todos eles, incluindo o saber científico, se podem enriquecer neste diálogo. Implica uma vasta gama de ações de valorização tanto do conhecimento científico como de outros conhecimentos práticos, considerados úteis, cuja partilha por pesquisadores, estudantes e grupos de cidadãos serve de base à criação de comunidades epistêmicas mais amplas que convertem a universidade num espaço público de interconhecimento onde os cidadãos e os grupos sociais podem intervir sem ser exclusivamente na posição de aprendizes (SANTOS, 2010, p. 57).

Frente ao exposto, é impossível falar de socialização de conhecimento (ensino: aprendizado) e produção de conhecimento (pesquisa: investigação), sem considerar a sua relevância política. É neste nível que a extensão adquire uma dimensão ética ao proporcionar atividades de intervenção que visam produções humanas e sociais, tornando-se componente intrínseco do ensino e da pesquisa no âmbito acadêmico.

Nessa amálgama, e considerando o processo de ensino, a extensão ocorre por meio de atividades que questionam a relevância social do conhecimento e no uso de metodologias que favoreçam a interdisciplinaridade. Já na pesquisa, a extensão ocorre quando a produção do conhecimento é capaz de contribuir com a problematização e a busca de respostas às demandas sociais, fortalecendo a relação da universidade com a comunidade externa. Nesse sentido, sempre que o estudante tem a oportunidade de integrar o conhecimento adquirido por meio do ensino e da pesquisa à atuação e ao diálogo com comunidades externas, estamos oportunizando a este estudante

\begin{tabular}{l|l|l|l|l|l|} 
@ C Revista Triângulo & Uberaba, Minas Gerais & v.12 & n.1 & p. 119-127 & 2019
\end{tabular}




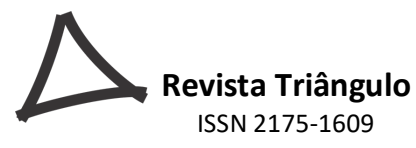

ISSN 2175-1609

uma experiência emancipatória e uma vivência de indissociabilidade (impacto na formação do estudante).

Ao questionar a relevância social do ensino e da pesquisa, a extensão traz importantes contribuições para o processo de ensino e aprendizagem, assim como, novas questões desafiadoras para a pesquisa ao considerar demandas reais (indissociabilidade ensino-pesquisa-extensão). Afinal, o que dá grandeza às instituições de ensino superior não é o que se faz dentro delas, mas sim, o que se faz com o que elas produzem (FERNANDES, 1966).

Em sintonia, no dia 14 de dezembro de 2018, o Ministério da Educação homologou a resolução que estabelece diretrizes para as ações de Extensão, considerando-a como componente curricular no ensino superior ao determinar o vínculo obrigatório dessas (mínimo de $10 \%$ da carga horária do curso de graduação) ao processo de formação e aprimoramento profissional. Coincidentemente, a resolução foi aprovada no ano do centenário da Reforma Universitária de Córdoba (1918) - um símbolo de ressignificação da universidade. Para os extensionistas, a resolução imprime, ainda, uma grande conquista e sinaliza um novo passo da institucionalização da extensão, desde a criação do Fórum de Pró-Reitores de Extensão (FORPROEX), em 1987. A normativa define conceitos, diretrizes e princípios para a extensão em todo o sistema de educação superior do país (público, privado e comunitário), bem como estabelece parâmetros de avaliação, registro e planejamento das ações extensionistas. Passam a ser consideradas ações extensionistas aquelas que envolvam diretamente as comunidades externas às Instituições de Educação Superior (IES) e que estejam vinculadas à formação do estudante. Esta, em seu Artigo $6^{\circ}$ (Capítulo I), traz os seguintes princípios que estruturam sua concepção e prática:

I - a contribuição na formação integral dos estudantes, estimulando formação do estudante como cidadão crítico e responsável;

II - o estabelecimento de diálogo construtivo e transformador om os demais setores da sociedade brasileira e internacional, respeitando e promovendo a interculturalidade;

III - a promoção de iniciativas que expressem o compromisso social das instituições de ensino superior com todas as áreas, em especial, as de comunicação, cultura, direitos humanos e justiça, educação, meio ambiente, saúde, tecnologia e produção, e trabalho, em consonância com as políticas ligadas às diretrizes para a educação ambiental, educação étnico-racial, direitos humanos e educação indígena;

IV - a promoção da reflexão ética quanto à dimensão social do ensino e da pesquisa; V - o incentivo à atuação da comunidade acadêmica e técnica na contribuição ao enfrentamento das questões da sociedade brasileira, inclusive por meio do desenvolvimento econômico, social e cultural;

VI - o apoio em princípios éticos que expressem o compromisso social de cada estabelecimento superior de educação;

v.12

n.1

p. 119-127 
VII - a atuação na produção e na construção de conhecimentos, atualizados e coerentes, voltados para o desenvolvimento social, equitativo, sustentável, com a realidade brasileira.

Acerca dos 10\%, é necessário ter clareza de que a incorporação da extensão no DNA da graduação não pode ser encarada como um adicional fragmentado e à margem da matriz, mas, como componente transversal, multidirecional e dialógico obrigatório entre a dimensão teórica e prática da formação dos estudantes (interdisciplinaridade e interprofissionalidade). Isso porque a extensão dá sentido prático (utilidade social) para o que se produz na academia. Por isso se faz necessário o movimento de teorizar a prática na extensão sob a égide do diálogo e da amorosidade, sem o tom de arrogância [de superioridade] e do ego [onisciente] dos pesquisadores.

Evidentemente, entender o papel da universidade e sua função social no prisma da Extensão é uma necessidade urgente e um desafio do século frente às três crises da universidade pública, apontadas por Santos (2010): crise de hegemonia, crise de legitimidade e crise institucional. Na interface destas, De Paula (2013, p. 20) contribui ao dizer que:

é tarefa da universidade para a sociedade, dialogar com ela, tentar responder às suas demandas e expectativas, reconhecer a sociedade, em sua diversidade, tanto como sujeito de direitos e deveres, quanto como portadora de valores e culturas tão legítimos quanto aqueles derivados do saber erudito. É tarefa da extensão construir a relação de compartilhamento entre o conhecimento científico e tecnológico produzido na universidade e os conhecimentos de que são titulares as comunidades tradicionais.

Diante dessas colocações, e como aborda Moacir Gadotti (presidente de Honra do Instituto Paulo Freire) em um provocativo texto, somos levados a seguinte indagação - "Extensão Universitária: Para quê?”. Ainda segundo referido autor, precisamos ter um pé dentro e outro fora da universidade, da mesma maneira, ter a escuta aberta, pois, não há um campo melhor e mais gratificante e inovador para o trabalho acadêmico do que na Extensão Universitária (GADOTTI, 2017, p. 14).

\section{CONSIDERAÇÕES FINAIS}

Ao refletirmos sobre a extensão nas instituições de ensino superior, o problema que se apresenta não é se esta ação é ou não extensão, mas a qualidade: onde e como se dá essa ação. 
Sobre a diretriz homologada, esta sela uma conquista de mais de 30 anos de debate, rompendo o vazio conceitual que a extensão trazia em seu bojo, sendo definida, historicamente, pela negação, ou seja, o que não é extensão. Embora esta tenha ganhado força nos últimos anos, ainda é interpretada sob o senso comum, sendo banalizada e desvalorizada no fazer acadêmico. Com um norte definido, tende-se a superar a visão equivocada de que extensão possui um caráter exclusivamente informal, ou seja, não exige rigor e vigor epistêmico.

Com isso, incorporar a extensão na nossa prática acadêmica exige, em primeiro lugar, disposição para dialogar, lembrando que este acesso nem sempre significa a inclusão do pensamento do Outro; e, ruptura de paradigmas, de vícios formativos e de um discurso que carrega consigo o olhar compartimentalizado, o qual é herdado de uma tradição que estratifica o saber em conhecimentos independentes. Essa cultura, marcada pelo habitus da visão cartesiana (estacionária), nos desafia a enxergar a extensão como fase móvel e fluída da formação humana, além de descolonizar o currículo.

Conforme reforça De Paula (2013, p.22), precisamos ver a extensão universitária como uma cultura, como uma prática, como um compromisso, indispensáveis à plena realização da universidade como instrumento emancipatório. Na dimensão pedagógica, a práxis extensionista é um dos mais ricos componentes de humanização; é o resgate do olhar crítico e consciente para o que ocorre além dos muros da academia. Ainda que muitos não foram formados em um modelo que utilizasse a extensão como agente transformador (humano e da realidade humana), precisamos interpelar o nosso "ser" formador sobre a responsabilidade social que nos é confiada.

Por fim, dicotomizar a universidade da sociedade é uma impossibilidade fácil de ser constatada, já que uma não existe sem a outra. Portanto, quando não conseguirmos mais distinguir o limite entre universidade e sociedade (ecótono extensionista), então teremos alcançado o tão sonhado e urgente nível de extensão universitária.

\section{REFERÊNCIAS}

BRASIL. Política Nacional de Extensão Universitária, 2012. Disponível em: http://proex.ufsc.br/files/2016/04/Pol\%C3\%ADtica-Nacional-de-Extens\%C3\%A3oUniversit\%C3\%A1ria-e-book.pdf. Acesso em: 01 set. de 2018.

CALDERÓN, A. I. Extensão universitária: institucionalização sem exclusão. Revista Educação Superior. Piracicaba: EDUNIMEP, v. 53, p. 36-38, 2003.

\begin{tabular}{l|l|l|l|l|l|} 
CC Revista Triângulo & Uberaba, Minas Gerais & v.12 & n.1 & p. 119-127 & 2019
\end{tabular}


FREIRE, P. Extensão ou comunicação? São Paulo: Paz e Terra, 2015.

FERNANDES, F. A democratização do ensino. In: BARROS, R. S. M. de (Org.). Diretrizes e Bases da Educação Nacional. São Paulo: Pioneira, p. 162-164, 1966.

GADOTTI, M. Extensão universitária: para quê? Artigo exclusivo, Instituto Paulo Freire, 2017. Disponível em: http://www.paulofreire.org/images/pdfs/Extens\%C3\%A3o_Universit\%C3\%A1ria_Moacir_Gadotti_fevereiro_2017.pdf. Acesso em: 05 out. de 2018.

GARCIA, P. B. Paradigmas em crise e educação. In: BRANDÃO, Z. (org.) Crise de paradigmas e educação. São Paulo: Cortez, 1995.

MONTEIRO, E.; SACRAMENTO, L. Para repensar a extensão universitária: contribuição do diálogo entre Paulo Freire e Boaventura de Souza Santos. Anais... Universidad del Litoral: Argentina, 2010. Disponível em: https://www.unl.edu.ar/iberoextension/dvd/archivos/ponencias/mesa2/pararepensar-a-extensao-uni.pdf. Acesso em: 05 out. de 2018.

PAULA, J. A. de. A extensão universitária: história, conceito e propostas. Interfaces - Revista de Extensão, v. 1, n. 1, p. 05-23, jul./nov., 2013.

SANTOS, B. de S. A Universidade no século XXI: para uma reforma democrática e emancipatória da Universidade. São Paulo: Cortez, 2010.

\begin{tabular}{|l|r|}
\hline & Recebido em: 6 Fev. 2018 \\
\hline Aprovado em: 18 Abr. 2019
\end{tabular}

